\title{
Determinants and Levels of Agricultural Development Agents \\ Job Satisfaction: The Case of Kalu Woreda, South Wollo Zone \\ of the Amhara National Regional State
}

\author{
Kaleb Kelemu ${ }^{1}$, Mekonnen Sime ${ }^{2}$, Mekonnen Hailu ${ }^{3}$ and \\ Turuwark Zalalam ${ }^{4}$
}

\begin{abstract}
This study was conducted with an objective of assessing the level of job satisfaction and its determinants among agricultural development agents working in different kebeles of Kalu Woreda, South Wollo Zone of the Amhara National Regional State. A total of 100 development agents were selected and interviewed using simple random sampling technique to collect data for the study through structured questionnaire. Descriptive and multiple regression methods were used to address the study objectives. Results of descriptive analysis showed that in terms of the level of job satisfaction of development agents on average development agents are 'undecided' with their job as a result of their involvement in special projects such as agriculture growth projects and donor-funded projects, in decision making, in in-service training and working relationship with farmers. The econometric results showed that there exists a statistically significant relationship between job satisfaction and recognition for best performances, rate of promotion, regular training and level of education of development agents. The study recommends that due attention needs to be given to defining career structure and provision of service training opportunities as criteria in promoting, improving and maintaining their job satisfaction.
\end{abstract}

Keywords: Job satisfaction, Development agent DOI: http://dx.doi.org/10.4314/ejbe.v4i1.5

${ }^{1}$ Kaleb Kelemu, Ethiopian Institute of Agricultural Research, kaleb_kelemu@yahoo.com, Tel; 251-911-686756

${ }^{2}$ Mekonnen Sime, Ethiopian Institute of Agricultural Research. mekonnensm@yahoo.com. Tel: 251-911-840458

${ }^{3}$ Mekonnen Hailu, Ethiopian Institute of Agricultural Research. mekonnen69@yahoo.co. Tel: 251-0910-326626

${ }^{4}$ Turuwark Zalalam, Lecturer, Bahir Dar University, tiruworkzelalem@gmail.com. Tel: 251-921-749060 
Job Satisfaction of Agricultural Development Agents

\section{Introduction}

The economy of Ethiopia is based on agriculture, which accounts for $46.3 \%$ of gross domestic product (GDP), 60\% of exports, and $80 \%$ of total employment. Many other economic activities depend on agriculture, including marketing, processing, and export of agricultural products. Because of this fact, development of the Ethiopian economy heavily depends upon the speed with which agricultural growth is achieved (Ashworth, 2005). Following the success of the Sasakawa Global-2000 scheme which resulted in a boom harvest in 1995, the government of Ethiopia adopted agricultural extension as a national intervention strategy and a major component of the Agricultural Developmentled Industrialization, ADLI, (Mathewos and Chandargi, 2005). Accordingly, the different development programs gave due emphasis to the development of the agricultural sector with a view to stimulating rapid growth in total production and improvement in productivity. In the Growth and Transformation Plan (GTP), the agricultural output is expected to grow with higher rate than in the last five years to achieve the target of doubling agricultural production by the end of the plan period (2015) and the source of increment is mainly through increased productivity. One of the main interventions employed to boost productivity has been the policy direction in the form of "Agricultural Technology Scaling Up" as part of the national initiative of "scaling up of best practices", which includes wider dissemination of already available agricultural technologies.

There have been significant changes undergoing in the agricultural extension service in the country in the last couple of decades. This mainly resulted from the commitment of the government towards agriculture in general and agricultural extension in particular through allocation of huge amount of 
Job Satisfaction of Agricultural Development Agents

budget and deployment of trained human resources and facilities. During the last few years, the government has made significant efforts to increase both the quantity and quality of extension service among rural farmers. This has been manifested through deployment of large number of development agents that are closely working with farmers. Currently, there are more than 60,000 development agents sharing their expertise to farmers according to their specialization. The development agents are not limited to serve farmers about resource management and farming techniques per se. Besides supporting and training farmers on resource management and improved farming techniques, they provide more services which directly or indirectly influence agricultural production and productivity. For instance, they provide a service of information and skill development, input supply, credit and saving, marketing of agricultural produce, etc (Gebremedhin et al., 2009).

As it is clearly stipulated in the agricultural extension strategy of the country, development agents are believed and expected to play crucial and multiple roles in the overall process of bringing about agricultural development in the country. They carry out several activities that aim at improving the living conditions of farmers. To the realization of the broader goals of the national extension program, the role of development agents deployed at each kebele (peasant association) has been very instrumental (Alemu and Demese, 2005). In view of this, the government of Ethiopia has launched an aggressive training program in 25 Agricultural Technical and Vocational Education and Training (ATVET) colleges established all around the country in the years 2003-2008 and managed to increase the number of extension agents to more than 60,000 . This was accompanied by the establishment of Farmer Training Centers (FTCs), each of which is meant to house three development agents with a 
Job Satisfaction of Agricultural Development Agents

range of technical skills, and provide a broad range of demand-responsive extension services and short-term training (MoARD 2009). The study conducted by Ananda and et al. (2005) indicates that besides knowledge and skill transfer, development agents are involved in credit distribution and collection of repayments, forecasting of input demands and input delivery, and kebele administration and adjudication. The multiple roles that development agents are currently playing signifies the great burden that they are shouldering and that bringing about change in the whole process of agricultural and rural development endeavors should target the effectiveness of development agents in delivering their responsibilities.

Nonetheless, development agents have been found to differ in perception and performance of their roles and satisfaction on their job (Ananda and et al.). Job connotes responsibility, duty, task and or paid position of a regular or part time payment (Hornby and Cowie, 1995). Satisfaction refers to a feeling of pleasure, the attainment of wants and needs, action of fulfilling desires and demand (Hornby and Cowie, 1995). Job satisfaction for development agents connotes the type of task and the feeling of attainment or fulfillment while performing duties as extension agents responsible for disseminating proven agricultural technologies. Job satisfaction can be defined as an individual's attitude about work roles and the relationship to worker motivation. Positive attitudes toward one's job are theoretically equivalent to job satisfaction and negative attitudes toward one's job are equivalent to job dissatisfaction (Oloruntoba and Ajayi, 2003).

Employees with higher job satisfaction levels believe that working in their organization will be satisfying in the long run, that they will care about the 
Job Satisfaction of Agricultural Development Agents

quality of their work, and that they will be more committed to the organization (Banmeke \& Ajayi 2005). The key to job satisfaction in the work place is to focus on changing those areas of work that employees want changed (Hackman \& Oldham, 2005). Since employee retention and turnover as well as effectiveness are related to one's level of job satisfaction, it is important to achieve good person-organization relationships by adapting jobs to people and adapting people to jobs (Hackman and Oldham, 2005). By doing this, employee job satisfaction levels and organization productivity increase, thus benefiting the employee and the employer (Oloruntoba, 2003).

Studying development agent's job satisfaction is important because effectiveness of the entire extension program being implemented throughout the country is influenced by the quality of the relationship between development agents and the extension work they do. If there is a good fit between development agents and their jobs, such that extension work is a personally rewarding experience, then there may be little for management to do to foster high motivation and satisfaction. On the other hand, if there is no good fit between development agents and their extension work and development agents are dissatisfied, then there may be little that extension management can do to produce high productivity and job satisfaction. Internal work motivation is tied closely with how well an employee performs on the job.

Lack of proper awareness of the operational realities could have a negative bearing on the level of satisfaction of the development agents on their jobs which could again influence their performance. Past studies are also deficient in providing pertinent information on this issue. A study by (Hackman and 
Job Satisfaction of Agricultural Development Agents

Oldham, 2005), also revealed the importance of addressing the relationship between development agents and their jobs. This study was, therefore, conducted to assess the level of satisfaction development agents have on their job and identify determinants of their satisfaction which ultimately determine their efficiency and effectiveness.

As the study was conducted in Kalu woreda only, the findings could not be generalized to the entire region as many specific circumstances and working environments, level of infrastructural development and other factors which would affect job satisfaction vary from woreda to woreda. But, the study could give important insights that are indicative of the possible situation in other woredas of the region. The study result, therefore; could be used by policy makers of Amhara National Regional State to introduce measures that motivate development agents working throughout the region.

\section{Theoretical Framework}

The concept of job satisfaction has been developed in many ways by many different researchers and practitioners. One of the most widely used definitions in organizational research is that of Locke (1976), who defines job satisfaction as 'a pleasurable or positive emotional state resulting from the appraisal of one's job or job experiences.' Others have defined it simply as how content an individual is with his or her job; whether he or she likes the job or not. It is assessed at both the global level (whether or not the individual is satisfied with the job overall), or at the facet level (whether or not the individual is satisfied with different aspects of the job). Spector (1997) lists 14 common facets: Appreciation, Communication, Coworkers, Fringe benefits, Job conditions, 
Job Satisfaction of Agricultural Development Agents

Nature of the work, Organization, Personal growth, Policies and procedures, Promotion opportunities, Recognition, Security, and Supervision).

A more recent definition of the concept of job satisfaction is from Hulin and Judge (2003), who have noted that job satisfaction includes multidimensional psychological responses to an individual's job, and that these personal responses have cognitive (evaluative), affective (or emotional), and behavioral components. Job satisfaction scales vary in the extent to which they assess the affective feelings about the job or the cognitive assessment of the job. Affective job satisfaction is a subjective construct representing an emotional feeling individuals have about their job. Hence, affective job satisfaction for individuals reflects the degree of pleasure or happiness their job in general induces. Cognitive job satisfaction is a more objective and logical evaluation of various facets of a job. Cognitive job satisfaction can be unidimensional if it comprises evaluation of just one facet of a job, such as pay or maternity leave, or multidimensional if two or more facets of a job are simultaneously evaluated. Cognitive job satisfaction does not assess the degree of pleasure or happiness that arises from specific job facets, but rather gauges the extent to which those job facets are judged by the job holder to be satisfactory in comparison with objectives they themselves set or with other jobs. While cognitive job satisfaction might help to bring about affective job satisfaction, the two constructs are distinct, not necessarily directly related, and have different antecedents and consequences. Job satisfaction can also be seen within the broader context of the range of issues which affect an individual's experience of work, or their quality of working life. Job satisfaction can be understood in terms of its relationships with other key factors, such as general 
Job Satisfaction of Agricultural Development Agents

well-being, stress at work, control at work, home-work interface, and working conditions.

Satisfaction refers to a feeling of pleasure, the attainment of wants and needs, action of fulfilling desires and demand (Hornby and Cowie, 1995). Job satisfaction for extension workers connotes the type of task and the feeling of attainment or fulfillment while performing duties as extension agents responsible for disseminating proven agricultural technologies. Role perception and job satisfaction connote the feeling of attainment or fulfillment by extension workers while performing their assigned tasks. Motivation has been noted to be imperative in ensuring job satisfaction which is considered as a pro-active human resource management strategy (Oloruntoba and Ajayi, 2003).

Herzberg's (1959) Motivation-Hygiene theory established how job satisfaction and dissatisfaction operate separately from one another. The MotivationHygiene theory differentiates among motivating and maintenance influences in the workplace. This theory states that satisfaction and dissatisfaction are driven by different factors - motivation and hygiene factors, respectively. An employee's motivation to work is continually related to job satisfaction of a subordinate. Motivation can be seen as an inner force that drives individuals to attain personal and organizational goals. Motivating factors are those aspects of the job that make people want to perform, and provide people with satisfaction, for example achievement in work, recognition, promotion opportunities. These motivating factors are considered to be intrinsic to the job, or the work carried out. Hygiene factors include aspects of the working environment such as pay, company policies, supervisory practices, and other working conditions. 
Job Satisfaction of Agricultural Development Agents

While Herzberg's model has stimulated much research, researchers have been unable to reliably empirically prove the model, with Hackman \& Oldham suggesting that Herzberg's original formulation of the model may have been a methodological artifact. Furthermore, the theory does not consider individual differences, conversely predicting all employees will react in an identical manner to changes in motivating/hygiene factors. Finally, the model has been criticized in that it does not specify how motivating/hygiene factors are to be measured.

Hackman and Oldham proposed the job characteristics model, which is widely used as a framework to study how particular job characteristics impact on job outcomes, including job satisfaction. The model states that there are five core job characteristics (skill variety, task identity, task significance, autonomy, and feedback) which impact three critical psychological states (experienced meaningfulness, experienced responsibility for outcomes, and knowledge of the actual results), in turn influencing work outcomes (job satisfaction, absenteeism, work motivation, and performance). The five core job characteristics can be combined to form a motivating potential score (MPS) for a job, which can be used as an index of how likely a job is to affect an employee's attitudes and behaviors. Not everyone is equally affected by the MPS of a job. People who are high in growth need strength (the desire for autonomy, challenge and development of new skills on the job) particularly affected by job characteristics.

Herzberg (1968) proposed that individuals are encouraged by motivators more than maintenance factors. Motivators include a stimulating vocation, accountability, and providing fulfillment from the profession, such as awards, 
Job Satisfaction of Agricultural Development Agents

accomplishment, or individual development. Maintenance influences include position, employment, income, and benefits, but these influences do not provide affirmative satisfaction, though dissatisfaction occurs from their deficiency (Hackman \& Oldham, 1976).

Darlene and Borman (1989) indicated that working environment such as physical surroundings, job satisfaction and management supervision, and workers' perceptions about these conditions can influence job performance. Job security and safety aspects such as pension scheme and workers' association, and organization policy and management style can produce different perceptions of workers about their working environment (Azril et'al., 2010). For instance, institutional policies and management styles that put so much pressure and supervision on their workers should be discouraged as they could create negative perception about the organizational policy among the employees.

Several factors influence the time allocation of employees at work. This study gives great emphasis to the effects on time allocation for work of the perceptions of AE workers' towards their working environment. Workers may have unique perceptions towards their working environment. These may include workers perceptions towards assigned tasks, individuals, interpersonal interactions, organizational standards, goals and regulations, physical location and prospects for rewards and incentives. The entire organizational environment (particularly as perceived by the organization members) is considered to have a very important impact on an individual's motivations, satisfactions and task performance (Newman, 1977).

EJBE Vol. 4 No. $1 / 2014$

Page 158 
Job Satisfaction of Agricultural Development Agents

Bennel and Zuidema (1989) indicated that the most important role of agricultural managers is to ensure proper utilization of agricultural workers with appropriate attitude, motivation and perception. Several studies investigated ways by which employees could be encouraged to apply greater effort to their tasks.

According to Herzberg et al. (1959) negative factors such as physical working conditions, poor pay, organizational policies, inter personal relations; and positive factors such as recognition by others substantially influence workers' job satisfaction and hence affect their working time. This in turn influences their job performance and agricultural productivity.

Some literatures written on the working conditions of extension agents reveal that in developing countries most development agents are working under difficult and disadvantageous conditions which led to job dissatisfaction and under performance. Fieldwork in many developing countries is characterized by conditions that foster low morale, lack of mobility, virtually no equipment and extremely low salaries. For many extension workers, tapping additional income sources is a question of physical survival (Nagel, 1997). These difficulties contribute to a high turnover rate; those who remain in extension are typically people with few employment opportunities elsewhere (Kaimowitz, 1991).

According to the study conducted by Opio-Odong (2000), in the majority of countries of sub-Saharan Africa, farmers show lack of confidence in extension workers. This is partly because agents are often instructed to transmit recommendations from research stations, which are formulated with little 
Job Satisfaction of Agricultural Development Agents

regard for smallholders or for the specifics of the extension agents' areas. Extension fieldwork, on the other hand, demands location specific, flexible and often quick decisions and actions.

In sub-Saharan Africa extension tends to lose its sense of mission. As one of the few government institutions with the broad coverage of the rural areas, extension agents are liable to be engaged in performing any task which fulfils ministerial policy at village level, be it supplying inputs and credit, transferring technology, feeding back information to research workers, mobilizing local communities for group action to solve community-wide problems, or dealing with specific farmer problems and referring them to specialists. Because policy objectives tend to outstrip the resources available to achieve them, this leads to overload on the agents. Moreover, it also leads them to trying to do jobs for which they have neither the training nor the experience. The resultant pressure of being expected to do more than they are able both quantitatively and qualitatively demoralizes the extension staff (Wiggins, 1986).

In a study conducted by Gebrehiwot et al. (2012), motivation is explained as description of person's motive to action. The assumption is that when development agents are motivated at their workplace it tends them to foster in serving people in agricultural extension services effectively. As a result, the outcome of the agricultural extension service they provide leads them to increase job satisfaction, effort, working environment, and creativity. In addition, everyone's full potential can be tapped so that the performance of development agents in serving their community in general and in technology dissemination in particular can be very high. The study underlines lack of adequate incentive system is a key factor for poor performance of development 
Job Satisfaction of Agricultural Development Agents

agents' in disseminating new technology to the intended smallholder farmers in SNNPRS.

A study conducted on time allocation of development agents on farmers field reveals that perceptions of extension workers about the fairness of performance appraisal, equality of male and female agents, job security, resource availability, and workload manageability significantly affected the time that agents worked on farmers' plots and there by their satisfaction on the job (Mekbib and Degnet, 2011). While off-the-job and on-the-job trainings and participation of extension workers in the agricultural planning process encouraged agents to work more on farms, better years of schooling and larger number of villages to work with had adverse effect on agents' working time. The study suggested that agricultural policy should capture and deal with the factors that affect the agents satisfaction and performance to ensure that extension agents are not only available but also adequately accessible to farmers. The study suggested that, more specifically, agricultural policy should capture elements that enhance motivation of development agents and introduce instruments that can bring improvement in the perception of extension agents about their working environment.

\section{Methodology}

\subsection{Description of Study Area}

The study was conducted based on the data collected from development agents working in Kalu Woreda. Kalu Woreda is located in South Wollo zone of the Amhara National Regional State, Ethiopia. It is bordered on the west by Dessie Zuria, on the north by Were Babu, on the south and east by the Oromia Zones, on the southeast by Argobba special woreda, and on the southwest by Abuko. 
Job Satisfaction of Agricultural Development Agents

The administrative center for this woreda is Kombolcha; other towns in Kalu include Ancharo, Gerba, Harbu and Degan.

The altitude of the woreda ranges between 800 meters above sea level in the lowlands bordering the Oromia Zone and 1,750 masl at the foot of the mountains north of Kombolcha. Its climate varies from dry sub-humid to semiarid. Important rivers include the Cheleleka and Borkana. Based on CSA (2007), the woreda has a total population of 186,181, an increase of $9.18 \%$ over the 1994 census, of whom 94,187 are men and 91,994 women; 19,810 or $10.64 \%$ are urban inhabitants. With an area of 851.54 square kilometers, Kalu has a population density of 218.64 , which is greater than the Zone average of 147.58 persons per square kilometer. A total of 41,648 households were counted in this woreda, resulting in an average of 4.47 persons to a household, and 40,115 housing units. In terms of religion $98.73 \%$ of the population is Muslim, while $1.17 \%$ are followers of Ethiopian Orthodox Christianity. The soils are generally fertile and range from sandy loam, loam to silty loam. The commonly practiced cropping system is mixedcropping. The major crops cultivated in the woreda include both rain fed and irrigated crops namely Maize, Millet, Tef, Fruits and Vegetables.

\subsection{Sampling}

The sampling frame for the study has been all the development agents deployed in kalu woreda. The sampling was done by taking into account the homogeneity of the population in terms of the incentive packages and associated elements and working environment that affect the motivation of development agents. Simple random sampling was used to draw the sample development agents from list of all development agents deployed in different kebeles of the woreda. The list was obtained from the woreda agriculture 
Job Satisfaction of Agricultural Development Agents

office. The total number of Development agents in the woreda is 155 and a total of 100 development agents were selected using simple random sampling technique. The selected development agents were interviewed using structured questionnaire with trained enumerators.

\subsection{Data Collection Techniques and Data Analysis}

Data has been collected using structured questionnaire. Before conducting the data collecting, the questionnaire was pre-tested on the field. The questionnaire was administered through enumerators. Intensive training was given to enumerators. Supervisors were assigned to monitor the data collection process to ensure the quality of data collected. SPSS software was used to analyze the data.

Ordinary Least Square (OLS) model has been used for estimating the unknown parameters in the linear regression model employed for analysis. The OLS was used as its estimator is consistent when the independent variables used are exogenous and there is no perfect multicollinearity. In addition, it is optimal in the class of linear unbiased estimators when the errors are homoscedastic and serially uncorrelated. Under these conditions, the method of OLS provides minimum-variance mean-unbiased estimation when the errors have finite variances.

The questionnaire was designed to capture 'job satisfaction scale' that was developed and used by Banmeke and Ajayi (2005). The scale was useful to collect data from the respondents to estimate the level of job satisfaction. Accordingly, the respondents were asked to rate 14 items that affect job 
Job Satisfaction of Agricultural Development Agents

satisfaction on a 5 point rating scale of very satisfied $=5$ points, satisfied $=4$ points, undecided $=3$ points, unsatisfied $=2$ points, and very unsatisfied $=1$ point. The mean satisfaction score of all the items was calculated. The level of job satisfaction was determined by dividing the grand mean satisfaction score of all the items by the number of items.

Then, the indices of satisfaction were used to construct a multiple regression model in order to analyze determinants of job satisfaction. The regression model has the form:

$$
\mathrm{Y}=f(X 1 \times 2 \times 3 \times 4 \times 5 \times 6 \times 7 \times 8 \times 9 U) \text {. }
$$

Where $Y=$ Job satisfaction score; $X 1=$ incentives $($ Payment of allowances $)(0$ if not regular, 1 if regular $) ; X 2=\quad$ Mobility $(0$ if not provided, 1 if provided); $X 3$ = No of farm households reached by Development Agents; $X 4=$ Rate of promotion ( 0 if not consistent, 1 if consistent); X5 = No of trainings attended since employed $; X 6=$ Age; X7 = Gender $(1=$ Male, $O=$ Female $)$; $X 8=$ Level of education (years); X9 =professional experience (Yrs) and $U=$ error term

Before and after model estimation, the following diagnostics tests were performed. First the data was checked for influential outliers. A multicollinearity test was performed using VIF on continuous variables and contingency coefficients on dummy variables. Tests for heteroscedasticity and finally model specification were also performed. 
Job Satisfaction of Agricultural Development Agents

\section{Results and Discussions}

\section{1 Demographic Characteristics of Respondents}

The demographic characteristics of the respondents of the study is described below. As it can be seen from table, the mean age of the sample development agents is 29.4. The average family size of the development agents is about 2.1. From the total number of respondents, 19 percent are female while the remaining 81 percent are male. By type of professional qualification, the proportion of development agents graduated with $10+1$ up to $10+3$ constitute $73 \%$ of the total sample. In terms of marital status $67.7 \%$ of the development agents are married while the remaining $32.4 \%$ are single. The work experience of the respondent's range from one to six years out of which $80 \%$ of the respondents have experience of above three years.

Table 1. Demographic characteristics of the sampled extension workers.

\begin{tabular}{llc}
\hline Description & & Development Agents \\
\hline Family size, mean & & 2.1 \\
Age, mean & & 29.4 \\
Marital status (\%) & Married & 67.6 \\
& Single & 32.4 \\
& Other (divorce/widow) & 0 \\
Sex (\%) & Male & 81 \\
& Female & 19 \\
Education Level & Total & 100 \\
& $10+1$ up to $10+3$ & 73.2 \\
& 12 up to $12+3$ & 24.5 \\
& Others & 2.3 \\
\hline
\end{tabular}

EJBE Vol. 4 No. 1/2014 
Job Satisfaction of Agricultural Development Agents

\subsection{Levels of Job Satisfaction}

Employees of an organization are simply the ones who give meaning, purpose and life to it. Without people organizations are simply empty buildings and unused equipment. Healthy and vibrant organizations are those with healthy and vibrant workers. Happy and vibrant workers are productive workers; and productive organizations are those with satisfied workers and conducive environment. Job satisfaction is an important ingredient for evaluating organization's success (Takele and Naredranath, 2013). Organizations have significant effects on the people who work for them and some of those effects are reflected in how people feel about their work. These effects could include commitment on tasks assigned, feelings of belongingness and ownership, innovativeness and improved performance and satisfaction in their job (Spector, 1997).

Accordingly, the findings of this study revealed that employees job satisfaction could be determined by different factors. Involvement in special projects, decision making, working relationship with farmers, in service training were found to be the major indicators of job satisfaction as the mean values of all these factors were found to be equal to 5 (see table 2). Development agents were also satisfied with their performance as development agents, working relations with supervisors at woreda, and access to research findings. The grand mean satisfaction score was 3.00 implying that development agents in the study area were 'undecided' with their job. Development agents were found very unsatisfied with the rate of promotion, salaries they are receiving, suitability of working environment such as housing, availability of communication facilities that help their extension work, and availability of local accommodation such as hotels and restaurants. Table 2 presents the 
Job Satisfaction of Agricultural Development Agents

summary of responses of the development agents to the various factors that affect their job satisfaction.

Table 2: Factors affecting and level of Job Satisfaction of the Development Agents

\section{Factors}

Involvement in special projects (AGP,

Joint NGO and government projects)

Length of stay in current station

Performance as Development Agent

Working relations with supervisors at

woreda level

Rate of promotion

Working relationship with farmers

Reward system (educational

opportunities, recognition)

Salaries being paid

Suitability of working environment

(housing)

In-service training

Involvement in decision making

Access to research findings

Communication facilities and work

facilities

Availability of local accommodation

Maximum Score

Grand Mean Score

\section{Mean}

5.00

3.00

4.00

4.00

1.00

5.00

2.00

1.00

1.00

5.00

5.00

4.00

1.00

1.00

42

3.00

\section{Standard Deviation}

0.55

0.69

0.48

0.47

0.53

0.59

0.56

1.02

0.68

1.04

0.39

1.01

1.17

1.19

EJBE Vol. 4 No. 1/2014

Page 167 


\subsection{Determinants of Job Satisfaction among Development Agents}

In order to determine factors that affect most the satisfaction of development agents in their present job, regression model was used. The results of the multiple regression analysis are presented on Table 3. The result shows that the coefficient of multiple determinations $\left(\mathrm{R}^{2}\right)$ was $71.2 \%$. This implies that the variables in the model were able to explain up to $71 \%$ of the variation in the level of Job Satisfaction among the development agents deployed at different kebeles of Kalu Woreda. The result also shows that recognition for best performances, promotion, trainings and level of education were significantly related to job satisfaction. This is because recognition for best performances leads to a greater degree of motivation and hence job satisfaction of development agents. In addition, the more development agents attend various regular trainings, conferences and workshops, the more they are able to update their knowledge and skill base in the areas of their assignment or job. Consequently, their level of satisfaction is expected to increase as a result of their ability to do their work better. The promotion of development agents to higher ranks increase their level of confidence with the organization and, hence, their level of job satisfaction. Irregular promotion leads to frustration and reduced interest in the job. The level of job satisfaction is also directly related to the level of education of the development agents, thus the higher the level of education, the higher the level of job satisfaction of the development agents. Three variables namely; number of farm families covered, age and number of years of experience of the development agents were found to be negatively related to the level of job satisfaction of development agents. The above implies that an increase or rise in any of the variables will lead to a decrease in the level of job satisfaction of the development agents. Reasons 
Job Satisfaction of Agricultural Development Agents

could be due to ageing, fatigue and boredom on the same job over a long period of time. The key informant interview conducted with woreda level official also showed that the place of residence and job of the development agents are less convenient for making decent life. This is mainly due to lack of infrastructure and basic social services. As a result they tend to be less satisfied with their job.

\section{Table 3: Result of the Multiple Regression Analysis}

$\begin{array}{ll}\text { Explanatory Variables } & \begin{array}{l}\text { Estimated Regression } \\ \text { Coefficients }\end{array}\end{array}$

\section{Constant}

Recognition for best

performances (X1)

Mobility (X2)

No. of farm families (X3)

Promotion (X4)

In-service-training (X5)

Age of development agents

(X6)

Gender (X7)

Level of education (X8)

Years of experience (X9)
2.29(0.43)

$0.41(0.12)$

9.22(0.12)

$-1.31(4.89)$

7.59(0.15)

9.10(0.19)

$-9.48(0.08)$

7.14(0.12)

2.87(0.49)

$-6.89(0.43)$
5.34

$3.65 * * *$

$76.83^{\text {NS }}$

$0.27^{\mathrm{NS}}$

$50.6^{* *}$

$45.44 * * *$

$-118.50^{\mathrm{NS}}$

Figures in brackets are standard errors. $\mathrm{R}^{2}=0.712 \mathrm{~F}$-value $=7.191^{* * *}$ $* * *$ - Significant at 1\%,** - Significant at 5\%, * Significant at 10\%, NS - Not significant 
Job Satisfaction of Agricultural Development Agents

In-service trainings offered to development agents at least once a year and several trainings that come along with donor funded projects were primarily mentioned as the most important factors that enhanced interest of the development agents that make them stay in their place of work. In-service trainings were organized regularly for the development agents and this has contributed to the satisfaction of development agents on their job. The inservice trainings are provided to development agents in all woredas of Amhara region. The other important factor mentioned was award being given for best performing development agents who raised their satisfaction. The program was started by the government very recently with an objective of giving recognition for best performing development agents with the purpose of influencing and motivating other development agents to do their job diligently. The program has been implemented by identifying the development agents from all round the region and certificate of recognition for best performance has been give. This has proved in many instances motivating development agents towards better performances and achievements. The development agents have also explained further the award to include some kind of material incentive along with the cetrificate.

\section{Conclusion and Recommendation}

This study was conducted to assess the determinants of development agents' job satisfaction in Kalu district. The responses from the development agents show they are neither 'satisfied' nor 'dissatisfied' rather were not able to decide on their satisfaction. This suggests that they are unsatisfied. According to the study result, it was found that a significant relationship exists between recognition of best performances, in-service training of development agents, promotion, level of education and the level of job satisfaction among 
Job Satisfaction of Agricultural Development Agents

development agents. According to Rao (1996), these variables can be categorized under human resource development (HRD) climate. HRD climate is an integral part and a component of the prevailing wider organizational climate, (Rao and Abraham, 1986; Akinyemi and Iornem, 2012,cited in Takele and Naredranath, 2013) that refers to perceptions about the prevailing conditions within an organization which affects the life of employees (work and personal life) and the activities within the organization (Sharma and Purang, 2000, and Srimannarayan, 2009 cited in Takele and Naredranath, 2013). Study finding by Takele and Naredranath (2013), confirmed that HRD climate and its elements have significant contribution to overall job satisfaction of employees. Accordingly, its sound to recommend the level of in-service and external trainings of development agents should be maintained and strengthened to enhance job satisfaction of development agents. Best practice recognition being implemented every year by government should be strengthened as it is found to be the most determinant factor that enhances job satisfaction of development agents. It is also recommended that the educational opportunities available for development agents need to be enhanced so that they can upgrade their educational level which increases their job satisfaction as well as performances. 
Job Satisfaction of Agricultural Development Agents

\section{References}

Akinbode, I.A. 1971. Roles of the Divisional Extension Officers in the Western State of Nigeria. Quarterly Journal of Administration: 6:21-22.

Ananda P, Dijkman J, Hoekstra D and Workneh S. 2005. Past, present and future of extension services. Paper presented at extension training workshop organized by the Improving Productivity and Market Success (IPMS) of Ethiopian Farmers project, May 23-25, 2005. ILRI (International Livestock Research Institute), Addis Ababa, Ethiopia. Alemu D and Demese C. 2005. The National Extension Intervention Program (NIEP) and sustainable agricultural development: An exploratory study to steer the debate on ADLI. In Negatu W, Dadi L, Hailegebriel A, Belete S and Gebremedhin B. (eds), Reversing vulnerability of rural livelihoods in Ethiopia: Options for sustainable development: Proceedings of the $7^{\text {th }}$ annual conference of the AESE (Agricultural Economics Society of Ethiopia), Addis Ababa, Ethiopia. AESE, Addis Ababa, Ethiopia.

Ashworth V. 2005. The challenges of change for agricultural extension in Ethiopia: A discussion paper. Federal Democratic Republic of Ethiopia, Addis Ababa, Ethiopia.

Azril MSH, Jegak U, Asiah M, Azman AN, Bahaman, AS, Jamilah O Thomas K (2010). Can Quality of Work Life Affect Work Performance among Government Agriculture Extension Officers? A Case from Malaysia. J. Soc. Sci., 6: 64-73.

Banmeke, T.O.A. and Ajayi, M.T. (2005). Job Satisfaction of Extension Workers in Edo State Agricultural Development Programme (EDADP), Nigeria, International Journal of Agriculture and Development, 6:202 $-207$. 
Job Satisfaction of Agricultural Development Agents

Central Statistical Agency 2007. Population and Housing Census Report -Country, 2007, , 2010-07, English, Ethiopia.

Darlene MO, Borman WC (1989). More Evidence on Relationships between the Work environment and Job Performance. Human Perform., 2: 113 $-130$

Gebremedhin B, Jaleta M, Hoekstra D (2009). Smallholders, institutional services, and commercial transformation in Ethiopia. Agricultural Economics, 40 (s1), 773-787.

Gebremedhin B., Hoekstra D and AzageTegegne. 2006. Commercialization of Ethiopian agriculture: Extension service from input supplier to knowledge broker and facilitator. IPMS (Improving Productivity and Market Success) of Ethiopian Farmers Project Working Paper 1. ILRI (International Livestock Research Institute), Nairobi, Kenya. 36 pp.

Gebretsadik, Haile Mekbib and Abebaw, Degnet. 2011: "What factors determine the time allocation of agricultural extension agents on farmers' agricultural fields?": Evidence from rural Ethiopia. Journal of Agricultural Extension and Rural Development Vol. 4(10), pp. 318-329, 6 June, 2012 . DOI: 10.5897/JAERD11.037, ISSN- 2141 -2154 @2012 Academic Journals.

Hackman, J. R. \& Oldham, G. R. 1976. Motivation through the design of work: Test of a theory. Organizational Behavior and Human Performance, 16, 250-279.

Hackman, J. R. \& Oldham, G. R. 2005. How job characteristics theory happened. The Oxford handbook of management theory: The process of theory development, 151-170.

Herzberg F. (1968). Motivation factors for employees. New York: Wiley, 
Job Satisfaction of Agricultural Development Agents

1964. PP. 214

Herzberg F., Mausner B. \& Snyderman B. The motivation to work. New York: Wiley, 1959. PP. 157

Hornby, A.S. and Cowie, A. P. 1995. Oxford Advance Dictionary of Current English 5th Edition Oxford University Press.

Hulin, C. L., \& Judge, T. A. 2003. Job Attitudes. In W. C. Borman, D. R. ligen, \& R. J. Klimoski (Eds.), Handbook of psychology: Industrial and organizational psychology (pp. 255-276). Hoboken, NJ: Wiley.

Kaimowitz, D. 1991. 'The Evolution of Links between Extension and Research in Developing Countries', in W.M. Rivera and D.J. Gustafson (eds.), Agricultural Extension: Worldwide Institutional Evolution and Forces for Change, Elsevier Science, Amsterdam, pp. 101-12.

Locke, E.A. 1976. The nature and causes of job satisfaction. In M.D. Dunnette (Ed.), Handbook of industrial and organizational psychology (pp.1297-

1349). Chicago: Rand McNally.

Mathewos B and Chandargi DM. 2003. Models for private and public extension cooperation as applicable to the Ethiopian system. In:

Tesfahun F and Osman A. (eds), Challenges and prospects of food security in Ethiopia, proceedings of the food security conference, 2003, Addis Ababa, Ethiopia.

MoARD (Ministry of Agriculture and Rural Development). (2009). Official documents and records from the Agricultural Extension Directorate. Addis Ababa: MoARD.

Newman J.E .1977. Development of a Measure of Perceived Work Environment (PWE). Acad. Manage J., 20: 520-534.

Oloruntoba, A. and Ajayi, M.T. 2003. Motivational Factors and Employees job Satisfaction in large scale private farms in Ogun State, Nigeria journal 
Job Satisfaction of Agricultural Development Agents

of International Agricultural and Extension Education, 10 (1): 67-72.

Opio-Odongo, J. 2000. 'Roles and Challenges of Agricultural Extension in

Africa' S.A. Breth (ed.), Innovative Extension Education in Africa, Sasakawa African Association, Mexico City, pp. 89-103.

Spector, P.E. 1997. Job satisfaction: Application, assessment, causes, and consequences, Sage, London.

Takele, M. and K. Naredranath. 2013. HRD Climate and job satisfaction of Ethiopia: An emperical study in Amhara and Benishangul Gumuz Regions. IOSR Journal of Business and Management (IOSR-JBM), volume 13 (11): 121-131.

Weldegebrial, Gebrehiwot, Asayehegn, Kinfe and Kaske, Deribe. 2012. "Challenges of Development Agents (DAs) Performance in Technology Dissemination": A Case from Southern, Nation, Nationalities and Peoples Regional State(SNNPRS), Ethiopia.

Scholarly Journal of Agricultural Science Vol. 2(9), pp. 208-216, September, 2012. ISSN 2276-7118 @2012.

Wiggins, S. 1986. 'Agricultural Policy and Agricultural Extension: The African Experience', in G.E. Jones (ed.), Investing in Rural Extension: Strategies and Goals, Elsevier Science, New York, pp. 99-105. 